\title{
Children's Emotion And Behavior In Painting Activities
}

\author{
I-Ju Chen, Chaoyang University of Technology, Taiwan
}

\begin{abstract}
This study adopted various methods such as qualitative research, observation, interviews, and document collection to examine the emotional responses, behavior changes, and counseling effects on a single-parent child in a skipped-generation family before or after a series of painting activities. The participant was asked to take part in 50-minute sessions twice a week for 8 weeks (16 unit activities in total). According our research findings, after the painting activities: (1) The subject in this study exhibited significant improvement in personal relationships, and there was a positive performance in social interaction, namely, more initiative and willingness to share with others; (2) The subject became more active in his family activities, and he tended to have more positive interactions with his grandmother; (3) The subject created significant positive changes in terms of inherent abilities, learning motivation, self-affirmation, and self development; and (4) The subject had significant improvement in learning performance in kindergarten; and (5) The subject's communication and expression skills were dramatically enhanced. During the painting projects, the subject did maintain good interactions with researchers and was very pleased to share more through self-disclosure. Hence, this study will provide conclusions and suggestions in accordance with these research findings, which can serve as a valuable reference for future research as well as for any pre-kindergarten teacher who is counseling children living in skippedgeneration families who are more likely to have poor social interactions.
\end{abstract}

Keywords: Art Therapy; Emotion Management; Behavior Guidance; Skipped-Generation Families

\section{INTRODUCTION}

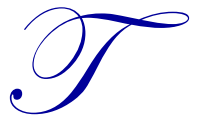

his study adopts a qualitative research method to explore the emotion management and behavior guidance for children living in skipped-generation families and to further examine the changes between young children's emotional behavior and social interactions before or after the painting activities. If a researcher tries to explore causes related to emotion management and behavior guidance for children living in skipped-generation families and would like to provide timely counseling, such researcher must carry out authentic context-based observations and conduct in-depth interviews with parents, teachers, students, or other associated educational staffs for collecting relevant data and supporting evidences.

\section{DURING THE STAGE OF ACTIVITIES}

The subject of this research was asked to participate in 50-minute sessions twice a week for 8 weeks, starting from October 1, 2009, with a total of 16 unit activities. In this study, all data related to painting activities were gathered by means of recording, video, and photography along with additional analyses and observations of the changes in the subject during the sessions. The activity plan could be adjusted according to the subject's actual conditions; hence, the observation period of relevant activities was preset to $8-10$ weeks.

\section{FAMILY SITUATIONS}

The subject of this study was a private kindergartener in Taichung City. After his parents' divorce, he was raised by his grandmother. His mother started a new family. Because he was the only child, he and his grandmother lived together and depended on each other. His grandmother did some handiwork at home to support the family of 
two, to make sure that the subject's education was not influenced by the family desertion. Although the subject often got into trouble, his grandmother still loved him the same. Because he was the only person his grandmother had, his grandmother cherished every moment spent with him.

\section{SCHOOL SITUATIONS}

Since attending the kindergarten, the subject had always been a pain in the neck for the teachers. The teacher of the class he was in described that his problems included being unable to concentrate, walking around during class, not being interested in learning, being impatient, taking other people's things, lying, and having bad interpersonal relationships. According to his pre-kindergarten teacher, the problems he had had included low frustration endurance, behavior such as beating people up when in a bad mood, damaging or taking other classmates' things, and lying. In addition, from the interviews with these two teachers, something common was found-the subject loved painting. The teachers and the grandmother worried about his issues and behavior involving social interactions such as:

(1) low learning motivation

(2) low frustration endurance and impatience

(3) passive and negative thinking

(4) getting mad easily and bad abilities to make communications or expressions, and

(5) lying and stealing

\section{RESEARCH TOOLS}

The qualitative research tool used is mainly the researcher himself, with auxiliary data collecting tools such as the "emotional behavior observation record", the "behavior and emotion scale", the "treatment-oriented painting activity and emotion feedback form", the "after-activity feelings feedback form", video taping, sound recording, and photographing. According to the researcher's experiences as a teacher, it was found that, to know a child's thoughts, painting is a good channel for it is a projection of the painter's mental needs. Painting is also an important way to let out emotions.

\section{DATA ANALYSIS}

The most significant feature of qualitative researches is that data are in the form of text instead of numbers. In a qualitative research, data collection and data analysis are usually performed at the same time. The largest difference between qualitative researches and other researchers is the nature of repeats of qualitative researches. The processes of qualitative researches are recurring. The following are the descriptions of the data analysis methods and the triangulation method used to check data used by the researcher in this study:

(1) Data analysis methods

In this study, data obtained from observation, interviews, and collected documents were examined word by word to find out possible meanings. Words or sentences were coded and categorized. The relationships between categories were explored and summarized. Finally, information obtained was collected to generate a report. How data collecting tools used in this study worked is listed below:

1. Emotional behavior observation record

2. Behavior and emotion scale

3. Treatment-oriented painting activity and emotion feedback form

4. Sound recording and video taping

5. The subject's paintings

6. After-activity feelings feedback form 


\section{(2) The triangulation method}

In this study, data collection and data analyses were performed at the same time. The data were coded in order to examine the relationships among them anytime, to explore their context and summarize the "meanings" within the data. When the data were analyzed, the triangulation method was adopted to examine and check the data, in order to increase the objectiveness and validity of the research results.

\section{RESEARCH CONCLUSION AND DISCUSSION}

When the subject received art treatment by participating in the painting activities, the research used the "behavior and emotion scale" to perform tests with the subject's grandmother, class teacher, and class mother. The purpose was to analyze the subject's changes in behavior and emotions after the painting activities of the art treatment through the test results of the key persons in the subject's life.

Before and after the subject received the art treatment by participating in the painting activities, his grandmother, class teacher, and class mother were asked to fill the "behavior and emotion scale" questionnaire, as shown in Table 2. Figure 1 shows the test results before and after the activities.

Table 1. The results of the "behavior and emotion scale" tests of the subject's key related persons

\begin{tabular}{|c|c|c|c|c|c|c|c|}
\hline Test name & \multicolumn{3}{|c|}{ Pre-test } & \multicolumn{4}{|c|}{ Post-test } \\
\hline $\begin{array}{l}\text { Behavior and } \\
\text { emotion scale }\end{array}$ & \multicolumn{3}{|c|}{ Standard score $(\mathrm{M}=100, \mathrm{SD}=15)$} & \multicolumn{4}{|c|}{ Standard score $(\mathrm{M}=100, \mathrm{SD}=15)$} \\
\hline $\begin{array}{l}\text { Behavioral } \\
\text { and } \\
\text { emotional } \\
\text { advantage } \\
\text { quotient }\end{array}$ & $\begin{array}{c}\text { Grandmother } \\
71\end{array}$ & & $\begin{array}{c}\text { /Class teacher } \\
74\end{array}$ & $\begin{array}{c}\text { Class mother } \\
76\end{array}$ & $\begin{array}{c}\text { Grandmother } \\
83\end{array}$ & $\begin{array}{c}\text { Class teacher } \\
87\end{array}$ & $\begin{array}{c}\text { /Class mother } \\
88\end{array}$ \\
\hline $\begin{array}{l}\text { Scale and } \\
\text { result }\end{array}$ & \multicolumn{3}{|c|}{ Standard score $(\mathrm{M}=10, \mathrm{SD}=3)$} & \multicolumn{4}{|c|}{ Standard score $(\mathrm{M}=10, \mathrm{SD}=3)$} \\
\hline $\begin{array}{l}\text { Interpersonal } \\
\text { relationship }\end{array}$ & 2 & 4 & 5 & 7 & & & 9 \\
\hline $\begin{array}{l}\text { Family } \\
\text { involvement }\end{array}$ & 4 & 5 & 5 & 8 & & & 8 \\
\hline $\begin{array}{l}\text { Inherent } \\
\text { abilities }\end{array}$ & 2 & 6 & 7 & 8 & & & 8 \\
\hline $\begin{array}{l}\text { School } \\
\text { performance }\end{array}$ & 5 & 4 & 5 & 8 & & & 9 \\
\hline $\begin{array}{l}\text { Emotional } \\
\text { performance }\end{array}$ & 5 & 6 & 5 & 10 & & & 9 \\
\hline
\end{tabular}

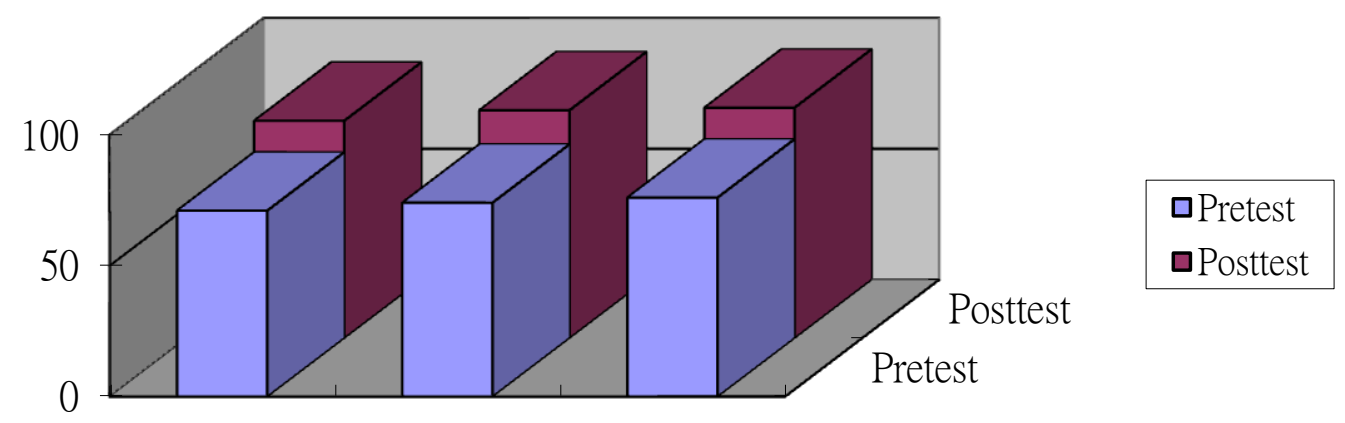

Grandmother Class teacher Class mother

Figure 2. The "behavioral and emotional advantage quotient" of the key persons in the subject's life 
The discussion below is based on Table 1 and Figure 2.

Analysis of the grandmother's "behavior and emotion scale” test result.

According to the grandmother's test result, the subject's "interpersonal relationship" and "inherent abilities" pre-test scores were both less than 3 standard deviations from the mean, which means that in these aspects, the subject was a pain in his grandmother's neck. After receiving the art treatment by participating in the painting activities, the subject's performance in "interpersonal relationship" and "inherent abilities" improved. In addition, the scores of "family involvement", "school performance", and "emotional performance" were less than around 2 standard deviations from the mean. After receiving the art treatment by participating in the painting activities, although the scores of "family involvement" and "school performance" were still lower than the averages, they increased. The change in "emotional performance" was the most significant. The score not only increased but also reached the average.

Analysis of the class teacher's "behavior and emotion scale” test result.

According to the class teacher's test result, the subject's "interpersonal relationship" and "school performance" pre-test scores were both less than 2 standard deviations from the mean, which means that the class teacher was worried about the subject in these aspects. And the scores of "family involvement", "inherent abilities", and "emotional performance" were less than 1 to 2 standard deviations from the mean. Thus, before receiving the art treatment by participating in the painting activities, the subject did not do as well as other children of the same age according to the class teacher's perception. However, after the painting activities were over, the post-test score of "emotional performance" increased and reached the average. Although the post-test scores of "family involvement", "inherent abilities", and "school performance" did not reached the averages, they still increased.

(3) Analysis of the class mother's "behavior and emotion scale" test result.

According to the class mother's test result, the subject's "interpersonal relationship", "family involvement", "school performance", and "emotional performance" pre-test scores were both less than 2 standard deviations from the mean, which means that the class mother was worried about the subject in these aspects. After receiving the art treatment by participating in the painting activities, the subject's performances in "interpersonal relationship", "family involvement", "school performance", and "emotional performance" improved. In addition, although the score change of "inherent abilities" was small, the score still had increased.

Comparison and analysis of the viewpoints of the subject's grandmother and teachers on the subject's behavioral and emotional changes.

Because it is not possible to clearly find out the influences of the subject's personality, the interactive factors, or the time factor, we can only be assume that from the viewpoints of the subject's grandmother, class teacher, or class mother, his behavioral and emotional performances both improved after receiving the art treatment by participating in the painting activities. 
Table 2. The observation records of the subject's emotions, behavior, and reactions during the painting activities of the treatment.

\begin{tabular}{|c|c|c|c|c|c|c|c|c|c|c|c|c|c|c|c|c|c|}
\hline \multicolumn{2}{|c|}{$\begin{array}{l}\text { Activity No. } \\
\text { Condition of interaction }\end{array}$} & 1 & 2 & 3 & 4 & 5 & 6 & 7 & 8 & 9 & 10 & 11 & 12 & 13 & 14 & 15 & 16 \\
\hline \multirow{6}{*}{$\begin{array}{l}\text { Expression of } \\
\text { emotions during } \\
\text { interaction }\end{array}$} & 1. Merry & & $\mathrm{O}$ & $\odot$ & $\mathrm{O}$ & $\odot$ & & $\mathrm{O}$ & $\mathrm{O}$ & $\mathrm{O}$ & & $\mathrm{O}$ & $\mathrm{O}$ & $\odot$ & $\odot$ & $\mathrm{O}$ & $\mathrm{O}$ \\
\hline & 2. Excited & & $\mathrm{O}$ & $\mathrm{O}$ & $\odot$ & & & & $\mathrm{O}$ & $\odot$ & & $\mathrm{O}$ & $\mathrm{O}$ & & $\odot$ & $\odot$ & $\odot$ \\
\hline & 3. Depressed & & & & & & $\odot$ & $\odot$ & O & & & & & & & & \\
\hline & 4. Anxious & & & $\mathrm{O}$ & $\mathrm{O}$ & & & $\mathrm{O}$ & $\mathrm{O}$ & & & & & & & & \\
\hline & 5.Losing temper & & & & & & & & & & & & & & & & \\
\hline & 6. Others & & & & & & & & & & & & & & & & \\
\hline \multirow{4}{*}{$\begin{array}{l}\text { Condition of } \\
\text { interaction with } \\
\text { the guiding } \\
\text { teacher }\end{array}$} & 1. Accepting guidance gladly & $\mathrm{O}$ & $\mathrm{O}$ & $\odot$ & $\odot$ & $\odot$ & $\mathrm{O}$ & & $\mathrm{O}$ & 0 & & $\odot$ & $\odot$ & $\mathrm{O}$ & $\mathrm{O}$ & $\mathrm{O}$ & $\odot$ \\
\hline & 2. Accepting guidance hardly & & & & & & & & & & & & & & & & \\
\hline & 3.Not accepting guidance & & & & & & & & & & & & & & & & \\
\hline & $\begin{array}{l}\text { 4. Showing attitude of } \\
\text { resistance }\end{array}$ & & & & & & & & & & & & & & & & \\
\hline \multirow{6}{*}{$\begin{array}{l}\text { Condition of } \\
\text { participating in } \\
\text { the painting } \\
\text { activity }\end{array}$} & $\begin{array}{l}\text { 1. Participating the activity } \\
\text { enthusiastically }\end{array}$ & & & $\mathrm{O}$ & $\mathrm{O}$ & $\odot$ & $\odot$ & $\mathrm{O}$ & $\mathrm{O}$ & $\odot$ & $\odot$ & & $\mathrm{O}$ & $\mathrm{O}$ & $\mathrm{O}$ & & \\
\hline & 2. Showing sign of tiredness & & & & & & & & & & & & & & & & \\
\hline & $\begin{array}{l}\text { 3. Not being able to complete } \\
\text { the activity }\end{array}$ & & & & & & & $\mathrm{O}$ & $\mathrm{O}$ & & & & & & & & \\
\hline & 4. Having problem focusing & & & $\mathrm{O}$ & $\mathrm{O}$ & & $\odot$ & $\odot$ & $\mathrm{O}$ & $\mathrm{O}$ & & & & & & & \\
\hline & $\begin{array}{l}\text { 5. Completing the activity } \\
\text { earlier sloppily }\end{array}$ & & & $\odot$ & & & $\odot$ & $\odot$ & $\mathrm{O}$ & & & & & & & & \\
\hline & $\begin{array}{l}\text { 6. Refusing to participate in the } \\
\text { activity }\end{array}$ & & & & & & & & & & & & & & & & \\
\hline \multirow{4}{*}{$\begin{array}{l}\text { Behavioral and } \\
\text { attitude } \\
\text { performance }\end{array}$} & 1. Speaking too loudly & & & & & & & & & & & & & & & & \\
\hline & 2. Being restless with anxiety & $\odot$ & $\mathrm{O}$ & & $\mathrm{O}$ & & $\odot$ & $\odot$ & $\mathrm{O}$ & & & & $\mathrm{O}$ & & $\mathrm{O}$ & & \\
\hline & 3. Leaving seat at will & & $\mathrm{O}$ & $\odot$ & & & $\mathrm{O}$ & $\odot$ & $\odot$ & & & & & $\mathrm{O}$ & & & \\
\hline & 4. Sabotaging one's own work & & & & & & & $\odot$ & & & & & & & & & \\
\hline \multirow{3}{*}{$\begin{array}{l}\text { Showing self- } \\
\text { respect and self- } \\
\text { confidence }\end{array}$} & $\begin{array}{l}\text { 1. Having the courage to show } \\
\text { one's own work }\end{array}$ & & & & & & & & & $\odot$ & $\mathrm{O}$ & & $\mathrm{O}$ & $\odot$ & $\odot$ & $\odot$ & $\odot$ \\
\hline & 2. Showing sign of happiness & & & & & & & & & & $\odot$ & $\mathrm{O}$ & $\odot$ & $\odot$ & $\mathrm{O}$ & $\odot$ & $\odot$ \\
\hline & 3. Expressing oneself properly & & & & & $\mathrm{O}$ & 0 & 0 & & 0 & $\odot$ & $\odot$ & $\odot$ & $\odot$ & 0 & $\odot$ & $\odot$ \\
\hline
\end{tabular}

Note:

1. "Empty space" means the situation was not the case in the interaction.

2. "O" means the situation was found but not significant.

3. " $\odot$ " means the situation was found and was significant. 
According to Table 2, with the increasing number of activities, the subject's emotional and behavioral reactions started to change as described below:

1. Expression of emotions during interaction.

During the 16 painting activities, the number of times the subject felt happy and excited increased while the number of times he felt anxious decreased. However, during the 6th, 7th, and 8th painting activities, the subject was depressed 5 times and anxious 4 times (The subject heard from his grandmother that his mother had given birth to a girl, so during the painting activity, he was obviously depressed). During the 16 painting activities, the subject never lost his temper. After summarizing all the records, it was found that the subject's emotional performance was stable during the activities.

2. Condition of interaction with the guiding teacher.

The positive feedbacks of the condition of interaction with the guiding teacher can be seen in Table 2 . During the interactions with the guiding teacher, the number of times the subject accepted guidance gladly increased. And he never "accepted guidance hardly", "not accepted guidance", or "shown attitude of resistance" during the activities.

3. Condition of participating in the painting activity.

In the beginning of the activities, the subject's activeness in participating was not obvious. Later, the activeness started to show. And during the 6th, 7th, and 8th activities, there were 12 times that the subject was not able to complete the activity, had problem focusing, or completed the activity earlier sloppily (The subject heard from his grandmother that his mother had given birth to a girl), representing rather low activeness in participating. However, after the 9th week, things became better. All these situations did not recur before the end of the activities. And the situations of showing signs of tiredness and refusing to participate in the activity never occurred during any of the 16 painting activities.

4. Behavioral and attitude performance.

The number of times the subject was restless with anxiety or left his seat at will decrease. In the later stage, he became more cooperative. However, according to the observation records shown in Table 3, it is obvious that during the 6th, 7th, and 8th activities, the number was rather high. Apparently during these 3 weeks, the subject's attitude and behavior were influenced. During the 16 painting activities, the subject never spoke too loudly. During the 7th painting activity, he destroyed his completed work once (The subject thought his work was ugly and therefore threw it away). After that, the same thing did not happen again.

5. Showing self-respect and self-confidence.

During the 16 painting activities, the most significant and effective change for the subject was the change in his self-respect and self-confidence. Improvements were evident in his having the courage to show his own work, showing signs of happiness, and expressing himself properly. The subject's largest gain from participating in these activities was his learning to show self-affirmation and share things with others.

The results of the interviews conducted by the researcher with the subject's grandmother and teachers.

1. Analysis and summary of the data from the interview conducted by the researcher with the subject.

During the painting activities in this study, the researcher interacted with the subject frequently. "Now I do my homework at home by myself", "I played with Mei yesterday and I did not hit her. She is my friend and I should take care of her", "I told grandmother that I was going to school. I will not cry anymore". During the interview with the subject, the subject could still trust the researcher as a guiding teacher as before. Based on the subject's responses, his interactions with others and adapting to the classroom environment improved after the painting activities of the art treatment. 
In addition, after the painting activities of the art treatment were completed, in order to further explore the subject's feelings about the activities, the researcher asked the subject to fill in the "after-activity feelings feedback form". The content of the feedback form was designed in 3 parts to explore the subject's feelings while painting and applications, emotion expression, and interactions with the guiding teacher. The 2nd and 3rd questions were openended questions. The subject had to answer them by writing down his changes in behavior, thoughts, and interactions with the guiding teacher after the activities.

2. The situations reflected by the results of the 2-point scale.

The reflected condition of the subject's "feelings while painting and applications"

According to the results of the "after-activity feelings feedback form", the subject had a positive viewpoint on feelings while painting and doing other applications. Paintings are like mirrors which can reflect children's feelings.

3. The reflected condition of the subject's "emotion expression".

According to the results of the "after-activity feelings feedback form", the subject had a positive viewpoint on emotion expression. This result is consistent with the purpose of art treatment, which, by expressing through art media, helps people explore themselves, accept themselves, open themselves, understand themselves, improve their cognition and self-respect, and balance their internal and external conflicts to achieve the effects of stabilizing emotions, bringing emotions to a higher level, and achieving better behavioral adaptation.

4. The reflected condition of the subject's "interactions with the guiding teacher".

According to the results of the "after-activity feelings feedback form", the subject had a positive viewpoint on the interactions through works. This result is consistent with the attitude the guiding teacher of the treatmentoriented painting activities must possess.

5. The situations reflected by the results of the open-ended questions.

According to the results of the "after-activity feelings feedback form", the subject improved himself and his interactions with others after the treatment-oriented painting activities and has done so until now. In addition, after the painting activities of the art treatment, according to the "messages to the teacher", with the care and guidance from the teachers, the subject changed from a person who did not know how to express his own feelings to a person who actively showed his gratitude.

The results from the interviews with the subject's grandmother about the changes in the subject after the treatment-oriented painting activities in emotion management and behavioral problems and the content of the "treatment-oriented painting activities and emotions feedback form" are analyzed and described below.

1. The aspect of emotions.

Before the painting activities of the art treatment, the subject sometimes destroyed things to show his anger when his grandmother was busy or out.

After the painting activities of the art treatment, the subject's emotion became more stable. The grandmother could strongly sense the change as the rebellious child became more obedient and polite.

2. The aspect of behavior.

Before the painting activities of the art treatment were conducted, the subject's behavioral problems had included lying, attacking, shouting, getting angry easily, being self-centered, and having low learning motivation. After the painting activities of the art treatment, the subject's learning attitude became more aggressive, his interactions with others became more active, his care for things around him became more positive, and his communication and expression abilities improved. 
3. The analysis of the results of the interviews conducted by the researcher with the class teacher and the content of the activities and emotions feedback form.

The class teacher had got along with the subject for over 2 years since the subject's infant school year till his kindergarten year. And the class teacher had good interactions with the subject's grandmother and class mother and was therefore aware of the subject's family background, learning performance, living habits, and interpersonal relationship.

(1) The aspect of emotion management.

Before the painting activities of the art treatment, the subject used to shout in class all the time with unstable emotions. After the treatment-oriented painting activities, the class teacher found that the subject's problem of shouting in class diminished. The subject's capability for emotion management seemed to increase.

The aspect of behavior.

Before the painting activities of the art treatment, the class teacher found the subject having problems such as having low learning motivation and low endurance of frustration, beating people up, losing temper easily, not being good at expressing and communicating, and lying. After the painting activities of the art treatment, the class teacher found him able to concentrate more in class and to interact with his classmates more often.

4. The analysis of the results of the interviews conducted by the researcher with the class mother and the content of the activities and emotions feedback form.

The kindergarten the subject attended was private, and there was a retarded child. The child's mother volunteered to help in the kindergarten in order to take care of her own child and share the teacher's burden. She had been doing this for over 2 years. Every noon this mother helped the kitchen mothers to cook lunch for the children in the kindergarten. The kindergarten saw this mother as one of them and was grateful for her selfless contribution. Therefore, this class mother often helped the subject during the after-school guidance. The class mother had got along with the subject for over 2 years. She had been patient and without regrets. Gradually, the subject started to depend on her like depending on a mother.

(1) The aspect of emotions.

Before the painting activities of the art treatment, the subject had had problems controlling his emotions according to the class mother. After the painting activities of the art treatment, the class mother found the subject's emotions more stable.

(2) The aspect of behavior.

Before the painting activities of the art treatment, the class mother thought the subject was an impatient and restless child. He lost his temper easily about small things. And he had behavioral problems such as insufficient learning motivation, making troubles, losing temper easily, and being distracted easily. After the painting activities of the art treatment, the frequencies of these behavioral problems decreased.

\section{GENERAL DISCUSSION}

1. The subject's changes in emotion and behavior.

Reviewing the subject's conversations with the researcher in the initial stage of the painting activities of the art treatment, the subject's words often showed that he was not confident with himself. Before painting, he was uneasy and doubtful with drifting eyes. In the initial stage, the characters in the subject's works were usually too small. And there were more apple trees and windows. According to this research, the subjected showed anxiety, could not feel safe, and wanted to be loved. After several painting activities of the art treatment, the subject became 
more self-confident. The fact that the subject loved painting was probably the reason why painting led to positive effects.

2. Possible factors which may have influenced the subject's emotion and behavior besides the painting activities.

In the process of the painting activities of the art treatment, other factors which may have influenced the subject's emotion and behavior include family member's support, guiding teacher's concern, and being accepted by others in interpersonal relationship development. Each is described below:

Family member's support.

The subject's parents divorced a long time ago. His mother had remarried, so currently he lived with his grandmother alone. The only family member he had was his grandmother. In order to pay for the subject's tuition and support the family, the grandmother had to work all day long doing some handiwork at home.

Guiding teacher's concern.

During the painting activities, the guiding teacher interacted with the subject with respect, support, care, acceptance, sincerity, and consistent attitude. In the initial stage, the guiding teacher lowered the subject's defiance by offering trust and respect, thus closing the distance between them. During the activities, the guiding teacher helped the subject to develop correct concepts, leading to the subject's improvements in emotion management and behavior.

(3) Being accepted by others in interpersonal relationship development.

Any information the subject received in the kindergarten may have influenced his emotions and the results of the painting activities of the art treatment. According to the researcher's observation, the tolerance, acceptance, and assistance from the subject's peers provided him a friendly environment to learn and grow, further increasing the stability of his emotions and the effects of the guidance.

\section{RESEARCH CONCLUSION}

The conclusions of this research are that after the painting activities, (1) in the aspect of interpersonal relationship, the subject's interpersonal relationship improved as seen in his positive behavior such as actively and willingly sharing things with others; (2) in the aspect of family involvement, the subject could actively participate in family activities and interacted with his grandmother with a positive attitude; (3) in the aspect of inherent abilities, learning motivations, self-affirmation, and self development, improvements were found; (4) the subject's school performance improved. Since the painting activities began, positive languages and thoughts increased gradually, and the subject cared more about his school performance and participated in groups more actively and gladly; and (5) the subject's ability of communication significantly improved. During the painting activities, the subject's interactions with the researcher were good. He was willing to show himself and share things with others. He was able to show emotions in front of others, accept others' praises, and shake hands with and hug others warmly. In sum, according to the research results, the "painting activities of the art treatment" conducted in this study were helpful for the improvements in children's emotion management and behavior guidance for them.

\section{RESEARCH SUGGESTIONS}

1. Suggestions for future researches.

(1) The aspect of research subjects.

The subject of this research was only one kindergartener. His emotion management and the behavior guidance for him were studied. If subjects of different genders but the same age can be studied by asking them to 
participate in the painting activities of the art treatment, the effects of the guidance may be similar in some ways or completely different. This issue is worthy of further study by researchers.

(2) The aspect of positioning the researcher's role.

The researcher played 3 roles in this study as the researcher, the observer, and the guiding teacher. Therefore, performing more insightful observation during the activities was not possible. Thus, in the future, if there can be an observer assisting in filming, recording, observing, and writing down records, assessment of children's involvement in activities and effects of guidance would be more objective.

The aspect of research duration.

In the aspect of research duration, the duration can be extended to make this research a long-term research, so that changes in the initial, middle, and final stages can be assessed, and the continuous influences after the research can be followed up.

2. Integrating manpower resources of the kindergarten for the guidance tasks.

The manpower resources of the kindergarten should be integrated to help preschool children who need help. Successful learning experiences are helpful to improve children's self-respect and self-confidence. In this study, the researcher and the teachers (the class teacher and the class mother) had continuously supported and encouraged the subject and found out the subject's problems and needs from various angles, so that the subject's emotion and behavior could be improved with everyone's effort.

\section{AUTHOR INFORMATION}

I-Ju Chen, Chaoyang University of Technology, Teacher Education Center, Taiwan. E-mail: crissa@cyut.edu.tw

\section{REFERENCE}

1. Blackburn, M. L. (2000). America's grandchildren living in grandparent households. Journal of Family and Consumer Sciences: From Research to Practice, 92 (2), 30-36.

2. Blatner, A. ( 1991 ) .Theoretical principles underlying creative arts therapies. The Art in Psychotherapy, 18 ( 5 ) , 405-409.

3. Corey, G. (1996). Theory and practice of counseling and psychotherapy ( $5^{\text {th }}$ ed.).Pacific Grove, CA: Brooks/Cole.

4. $\quad$ Campbell, J. (1993). Creative art in groupwork. Oxford, U.K.: Winslow Press.

5. Dannison, L.; Smith, A. B. \& Tammy, V. H. (1998). When "grandma" is "mom" what today's teachers need to know. Childhood Education, 75, 12-16.

6. Day, E. D., \& Remigy, M.J. ( 1999 ) .Mexican and French children's conceptions about family: A development approach. Journal of Comparative Family Studies, 30(3), 95-112.

7. Edwards, Oliver W \& Daire, Andrew P. ( 2006 ). School-Age Children Raised by Their Grandparents: Problems and Solutions, Journal of Instructional Psychology, 33 ( 2), 113-119.

8. Gerteisen, J. ( 2008 ) .Monsters, Monkey,\& Mandalas: art therapy with children experiencing the effects of trauma and fetal alcohol spectrum disorder. Art Therapy: Journal of the American Art Therapy Association, 25, 90-93.

9. Harris, P. R. 1983. New Worlds, New Ways, New Management. Ann Arbor: Masterico Press/ AMACOM.

10. Hirshorn,B.A. ( 1998 ) .Grandparents as caregivers. In M.E. Szinovacz (Ed.), Handbook on grandparenthood, P200-214. Westport, CT: Greenwood.

11. Jung, C. (1964). Man and his symbols. London: Aldus Books.

12. Liebmann, M. ( 1991). Art therapy for groups: a hand book of themes, games and exercises. London: Routledge.

13. Lusebrink,V.B. ( 1991 ) .A system oriented approach to the expressive therapies: The expressive therapies continuum. The Arts in Psycho-therapy, 18 ( 5 ) , 395-403. 
14. Mcwhinnie, H.J. (1985). Carl Jung and Heinz Werner and implications for foundational studies in art education and art therapy. The Arts in Psychotherapy, 12, p5-p9.

15. Mills,T.L.(2001). Grandparents and grandchildren: Shared lives, well-being, and institutional forces influencing intergenerational relationships-An epilogue to the special issue. Journal of Family Issues, 22(5), 677-679.

16. Raghurman, R. S. ( 1999 ) . Battling Separation Anxiety. American Journal of Art Therapy, 1 (37), 1-9.

17. Robin, J. A. (1984). Child art therapy (2nd ed.). New York: Van Nostrand Reinhoid.

18. Rubin,J.A ( 1987 ) .Approaches to Art therapy-theory and technique ( 2nd ed.) New York:

Brunner/Mazel.

19. Smith, G.C. and P. A. Palmieri ( 2007 ) .Risk of Psychological Difficulties: Among Children Raised by Custodial Grandparents, Psychiatric Services, 58 (10) 1303-1310.

20. Stamatelos, T., \& Mott, D.W. (1983). Art as a client- centered treatment modality.

21. Wadeson, H. (1980). Art psychotheraphy. New York: John Wiley \& Sons.

22. Waller,J.\& Gilroy,A. ( 1994 ) .Art therapy: A handbook. Buckingham: Open University Press.

23. Whooley, M. A., Kiefe, C. I., Chesney, M. A., Markovitz, J. H., Matthews, K., \& Hulley, S. B.(2002). Depressive symptoms, unemployment, and loss of income. Archives Internal Medicine, 162, 2614-2620.

24. Williams, G.H., \& Wood, M.M. (1977). Developmental art therapy. Baltimore: University Park Press.

25. Zinker, J. (1977). Creative process in gestalt therapy. New York: Brunner / Mazel. 
NOTES 